American Journal of Pharmacology and Toxicology 3 (1): 30-43, 2008

ISSN 1557-4962

(C) 2008 Science Publications

\title{
Hormetic Interventions in Aging
}

\author{
Suresh I.S. Rattan \\ Laboratory of Cellular Ageing, Department of Molecular Biology, \\ University of Aarhus, DK8000 Aarhus-C, Denmark
}

\begin{abstract}
Single or multiple exposure to low doses of potentially harmful agents can have a variety of anti-aging and longevity-extending hormetic effects. These hormetic stressors include irradiation, physical activity, food limitation, heat, hypergravity, dietary components and reactive oxygen species. Molecular mechanisms facilitating the hormetic effects are being elucidated and comprise a cascade of stress response and maintenance and repair pathways. Although the extent of immediate hormetic effects after exposure to a particular stress may only be moderate, the chain of events following initial hormesis leads to biologically amplified effects that are much larger, synergistic and pleiotropic. A consequence of hormetic amplification is an increase in overall defence capacity of cells and organisms. Therefore, healthy aging may be achieved by hormesis through mild and periodic, but not severe or chronic, physical and mental challenges and by the use of dietary hormesis incorporating mild stress-inducing molecules called hormetins. However, prescribing a practical anti-aging hormetic regimen comprising physical, chemical, dietary and psychological stressors requires detailed information akin to that needed to develop personalized medicine.
\end{abstract}

Key words: Aging, anti-aging, exercise, heat shock, homeostasis, homeodynamics, hormetin, longevity, stress

\section{INTRODUCTION}

Biogerontological research has now established that the primary molecular phenotype of aging is the occurrence and accumulation of intra-cellular and intercellular molecular damage ${ }^{[1]}$. The main reason for the age-related accumulation of molecular damage is the inefficiency of maintenance and repair pathways which normally comprise the homeostatic or homeodynamic ability of living systems. Aging, age-related diseases and eventual death are manifestations of unsuccessful homeostasis and failure of homeodynamics ${ }^{[1-3]}$.

A critical component of the homeodynamic property of living systems is their capacity to respond to stress. In this context, the term "stress" is defined as a signal generated by any physical, chemical or biological factor (stressor), which in a living system initiates a series of events necessary to counteract the damage, adapt to the altered conditions and continue to survive. While successful and compensatory responses to low doses of stressors improve the overall homeodynamics of cells and organisms, an incomplete or failed homeodynamic response leads to the damaging and harmful effects of stress, including death. Thus it is hypothesized that if biological systems are intentionally exposed to low levels of stress which causes some damage, which in turn will activate various homeodynamic pathways of maintenance and repair, this would lead to enhanced removal of damage and further protection against new damage. Such repetitive exposures to mild stress which can be successfully counteracted without becoming bioenergetically too costly to survive, would result in achieving beneficial effects, including health- and longevity-promotion $^{[4-9]}$. Thus hormesis in aging is defined as the life supporting beneficial effects resulting from the cellular responses to single or multiple rounds of mild stress ${ }^{[10-14]}$.

What follows is a review and analysis of the published literature on various physical, chemical and biological conditions which are known to be potentially harmful at high doses, but which, at lower doses, may have the effects of slowing down aging and/or prolonging the lifespan of cells and organisms. It is important to point out that so far only a few studies have been performed with a specific aim to test the applicability hormesis in aging, for example thermal stress and hypergravity. However, for most other studies, which are interpreted to involve hormesis as the mode of action of the stressful conditions used in those experiments, these conclusions are generally derived in retrospective analyses. Such studies include the effects of radiation, exercise, pro-oxidants, nutritional components and food restriction ${ }^{[15]}$. 
Am. J. Pharm. \& Toxicol., 3 (1): 30-43, 2008

\section{THERMAL HORMESIS IN AGING}

Thermal hormesis in organisms: Temperature stress, especially heat stress (HS), is one of those stresses that have been used with a specific aim to test and apply hormesis in aging research and interventions. One of the main reasons for choosing HS as a hormetic agent is that HS acts through an evolutionarily highly conserved stress response pathway known as the heat shock response, the molecular basis of which are pretty well understood $^{[16,17]}$. Effects of mild and severe HS have been tested on yeast, nematodes, fruitflies and on rodent and human cells. For example, a $2 \mathrm{~h} \mathrm{HS}$ at $37^{\circ} \mathrm{C}$ applied before the first division and after the fourth division slightly extended the replicative lifespan of Saccharomyces cerevisiae ${ }^{[18]}$. The same HS had no effect if applied later in life as well as if applied everyday.

In the case of nematode worms, wild-type and age-1 long-lived mutant hermaphrodite Caenorhabditis elegans exposed for 3 to $24 \mathrm{~h}$ to $30^{\circ} \mathrm{C}$ exhibited a significant increase in mean lifespan compared to controls ${ }^{[19,20]}$. Similarly, a $6 \mathrm{~h}$ exposure at $30^{\circ} \mathrm{C}$ of wildtype worms increased their lifespan, but no effect was found after exposures of 2 or $4 \mathrm{~h}^{[21]}$. Furthermore, C. elegans subjected to $35^{\circ} \mathrm{C}$ HS for different durations showed that HS not longer than $2 \mathrm{~h}$ produced resulted in an extension of lifespan ${ }^{[22-24]}$. In a study of multiple stresses in C. elegans an extension of lifespan after 1 and $2 \mathrm{~h} \mathrm{HS}$ at $35^{\circ} \mathrm{C}$ was reported ${ }^{[25,26]}$. In another study performed on C. elegans it was observed that repeated mild heat treatments throughout life had a larger effect on lifespan compared to a single mild heat treatment early in life and the effect was related to the levels of heat shock protein (HSP) expression ${ }^{[27]}$.

In the case of fruitflies, virgin males of inbred lines of Drosophila melanogaster exhibited an increase in mean lifespan and lower mortality rates during several weeks after a heat treatment of $36^{\circ} \mathrm{C}$ for $70 \mathrm{~min}^{[28]}$. No beneficial effect of HS was reported in females or in mated flies. It has also been shown that wild-type D. melanogaster exposed $5 \mathrm{~min}$ a day, 5 days a week for one week to $37^{\circ} \mathrm{C}$ lived on average 2 days longer than the control flies ${ }^{[29]}$. Longer exposures had either no effect or negative effect on lifespan. In another study on D. melanogaster, exposure of young flies to four rounds of mild $\mathrm{HS}$ at $34^{\circ} \mathrm{C}$ significantly increased the average and maximum lifespan of female flies and increased their resistance to potentially lethal $\mathrm{HS}^{[30]}$. Interestingly, the beneficial effects of HS in Drosophila do not entirely depend on a continuous presence of HSP, but are observed long after newly synthesised HSP had disappeared, indicating the involvement of a cascade of post-stress events in hormesis ${ }^{[31-33]}$.
Studies have also been performed on the effect of subjecting transgenic D. melanogaster over-expressing the inducible HSP70, to $20 \mathrm{~min}$ at $36^{\circ} \mathrm{C}^{[34,35]}$. In the control parental line, such an exposure significantly increased the lifespan of both virgin flies kept in groups and of mated flies. The effect was more pronounced in males than in females. In individually kept flies, the same trend was observed but was statistically not significant. No beneficial effect of such HS has been seen in the transgenic lines ${ }^{[35]}$. At least one study also reports the beneficial effects of cold stress-induced hardening in Drosophila, in terms of improved survival $^{[36]}$.

In the case of mammals, irradiated and nonirradiated mice who were given intermittent coldshocks showed lower rates of mortality in irradiated mice. Longer lifespans were observed in thermally stressed non-irradiated males and irradiated females ${ }^{[37]}$. Similarly, rats kept in water set at $23^{\circ} \mathrm{C}, 4 \mathrm{~h}$ a day, 5 days a week had a $5 \%$ increase in average lifespan and diminished the occurrence of certain age-related diseases $^{[38]}$.

Thermal hormesis in human cells in culture: A series of studies performed in our labs have tested the hormesis hypothesis of the beneficial effects of mild HS using the Hayflick system of cellular aging of normal human cells in culture ${ }^{[39]}$. Employing a mild stress regimen of exposing serially passaged human skin fibroblasts to $41^{\circ} \mathrm{C}$ for $1 \mathrm{~h}$ twice a week throughout their replicative lifespan, we have reported several antiaging effects. These effects include the maintenance of youthful morphology, reduced accumulation of oxidatively- and glycoxidatively-damaged proteins and increased resistance to ethanol, hydrogen peroxide and UV-A irradiation ${ }^{[40-44]}$. Possible mechanisms for the above hormetic effects of repeated mild HS in human fibroblasts include an increase in the activities of the proteasome, increased levels of various HSP and increased antioxidative enzyme activities ${ }^{[44,45]}$. Furthermore, we have also shown that repeated mild HS at $41^{\circ} \mathrm{C}$, but not the relatively severe $\mathrm{HS}$ at $42^{\circ} \mathrm{C}$, increased the replicative lifespan and elevated and maintained the basal levels of MAP kinases JNK1, JNK2 and p38 in human skin fibroblasts ${ }^{[46]}$.

In order to confirm the wider applicability of mild HS-induced hormesis in other human cell types, we have also performed studies on normal human epidermal keratinocytes (NHEK) and the results obtained are very much similar to those for dermal fibroblasts. As previously observed for human skin fibroblasts, NHEK also showed a variety of cellular and biochemical hormetic anti-aging effects on repeated 
exposure to mild $\mathrm{HS}$ at $41^{\circ} \mathrm{C}$. These effects included maintenance of youthful cellular morphology, enhanced replicative lifespan, enhanced proteasomal activity and increased levels of $\mathrm{HSPs}^{[47]}$. Additionally, we have also studied the effects of HS on Na,K-ATPase or the sodium pump. Mild HS significantly increased the content and activity of the pump in NHEK ${ }^{[47]}$. Increased $\mathrm{Na}, \mathrm{K}-\mathrm{ATPase}$ activity is consistent with an overall increase in the metabolic rate of the cell. However, the molecular mechanisms and interactions which bring about the mild HS-induced increase in the amounts and activity of $\mathrm{Na}, \mathrm{K}$-ATPase and its consequences on other biochemical pathways, in NHEK during aging are yet to be elucidated. Notably, comparable hormetic effects could not be seen in NHEK repeatedly exposed to $43^{\circ} \mathrm{C}$, which underlines the differences between the beneficial effects of mild stress and the harmful effects of severe stress. Other hormetic effects of mild HS on NHEK include increased differentiation of keratinocytes in the presence of calcium and reduced cytotoxic effects of glucose and glyoxal ${ }^{[48]}$.

We have now initiated studies on testing the hormetic effects of HS on the wound healing capacity of skin fibroblasts and on the angiogenic ability of endothelial cells ${ }^{[49]}$. Experiments to determine the effects of mild $\mathrm{HS}$ at $41^{\circ} \mathrm{C}$ for $1 \mathrm{~h}$ on the extent of wound closure in vitro showed that HS-induced production of secretory proteins enhanced wound healing by $20-40 \%$. In the case of angiogenesis by endothelial cells, as measured by the standard tube formation assay on matrigel, a prior exposure to mild HS increased the total tube length and total number of junctions by $30-60 \%$ and $10-14 \%$, respectively. In contrast, a severe heat shock at $42.5^{\circ} \mathrm{C}$ had slightly inhibitory effects on total tube length and the number of junctions ${ }^{[49]}$. These data add to the ever growing body of evidence in support of the view that mild stressinduced hormesis can be a useful approach for the modulation, intervention and prevention of aging and age-related impairments in human cells.

As regards the molecular mechanisms through which the hormetic effects of mild HS are achieved, these remain to be elucidated. Although the general mechanisms of severe HS response are well understood $^{[16,17]}$, it is not clear whether there are any significant differences between mild HS which has hormetic effects and severe HS repeated exposure to which has deleterious effects ${ }^{[50]}$. It is likely that the physiological cost of stress in terms of energy utilisation, molecular damage overload and metabolic shift determine the difference between the outcome of mild and severe stress. Also, it is yet to be understood how the transient appearance of HSP leads to biologically amplified hormetic effects at various other levels of cellular functioning, such as improved proteasome activity, enhanced resistance to other stresses and maintenance of the cytoskeletal integrity ${ }^{[14]}$.

\section{RADIATION HORMESIS IN AGING}

Biologically beneficial effects of low dose radiation (LDR) have been claimed and challenged since the discovery of X-rays. Since most of the experiments on the effects of irradiation on biological systems were performed to establish their harmful and dangerous effects, the beneficial and hormetic effects of irradiation were often ignored for a long time (for historical background ${ }^{[51]}$.

Radiation hormesis in insects: One of the earliest studies to show the life prolonging effects of irradiation were performed on flour beetle, Tribolium confusum, in which repeated exposure of beetles to low doses of $\mathrm{X}$ rays $(100-500 \mathrm{~mA} / \mathrm{min}$ at $25 \mathrm{~cm}$ at $50 \mathrm{kV})$ reduced their death rates as compared with unexposed organisms ${ }^{[52,53]}$. Similar observations on the lifeextending effects of gamma-rays and X-rays on flour beetles were later reported by other authors ${ }^{[54,55]}$. Other insects used for similar studies are the housefly, Musca domestica and the fruitfly, Drosophila. For example, whereas high doses of radiation decreased the lifespan, LDR extended the lifespan of fruitflies ${ }^{[56,57]}$ and of houseflies ${ }^{[58]}$. It has been argued that irradiation leads to female sterility and that the lifespan increase was an outcome of decreased fecundity. It was also shown that mutant females without ovaries did not exhibit increased lifespan after irradiation. The environmental conditions influenced the lifespan of male houseflies differently after an exposure to $\mathrm{LDR}^{[58]}$. The increased lifespan was observed only when animals were reared in groups, which promoted a high locomotor activity. However, if individually reared and assumed to have a low locomotor activity, flies did not show longer lifespans. Furthermore, irradiated flies had longer lifespan than controls only when the latter were kept on sub-optimal rearing conditions. The long-term consequences of the X-irradiation of Drosophila eggs demonstrated longevity hormesis in male flies exposed to $0.5 \mathrm{~Gy}$ and $0.75 \mathrm{~Gy}$, who also had smaller amounts of DNA segments resulting from cleavage in S1 nuclease sensitive sites ${ }^{[59-61]}$. One explanation given for the life-extending effects of LDR in insects is that irradiation induces stable epigenetic DNA modifications and enhanced DNA repair capacity $^{[51,59-61]}$. 
Radiation hormesis in rodents and other animals: Several studies have reported the hormetic effects of gamma rays on longevity in rats, mice and guinea pigs $^{[62,63]}$. Suppression of thymic lymphoma induction and prolongation of lifespan associated with immunologic modification by chronic LDR in C57BL/6 mice have been reported ${ }^{[64,65]}$. In contrast to this, some earlier studies had failed to show an increase of lifespan after a LDR. For instance, deuteron-irradiated mice exhibit higher mortality rates and lower lifespan in both sexes than non-irradiated ones ${ }^{[66]}$.

There are some data available on the effects of LDR on the survival and longevity of the nematode C. elegans. For example, an increase in the survival of C. elegans was sometimes observed after intermediate levels of irradiation ${ }^{[67]}$. However, pretreatment with ultraviolet or ionizing radiation did not promote subsequent resistance or increased longevity of the worms exposed to other hormetic stresses such as heat, hyperbaric oxygen and prooxidants ${ }^{[25]}$.

Radiation hormesis in humans: The adaptive response of human embryonic cells to low dose gamma-radiation has been shown to increase the replicative lifespan by up to $160 \%$ compared to nonirradiated cells ${ }^{\left[{ }^{[8]}\right.}$. Similarly, human embryonic lung diploid fibroblasts sequentially irradiated with $1 \mathrm{~Gy}$ gamma rays had their replicative lifespan increased to some extent ${ }^{[69]}$. Hormetic effects of low dose Xirradiation on the proliferative ability, genomic stability and activation of mitogen-activated protein kinase pathways have been reported for other human diploid cells $^{[70-73]}$.

In the case of human beings, although there are some claims that exposure to LDR has anti-aging and other health benefits such as cancer prevention, the demographic data are insufficiently precise to be conclusive $^{[6,74]}$. For example, although better survival and other beneficial effects of low to intermediate doses of atomic bomb radiation on Hiroshima and Nagasaki survivors have been claimed ${ }^{[75-77]}$, these results have been challenged by later analyses ${ }^{[78]}$. On the other hand, mortality rates of all workers in UK's Atomic Energy Authority were found to be lower than national rates ${ }^{[79]}$. All cause mortality and all cause cancers (leukaemia and prostate cancer) were also significantly lower for nuclear workers than for non-radiation workers ${ }^{[79]}$. In an earlier study analysing the varying levels of environmental radiation and incidence of cancer in different parts of India, it was reported that the regions such as Kerala where the background radiation level was higher due to rich coastal thorium-monazite deposits, the cancer risk was invariably less ${ }^{[80]}$. Recent analyses of a series of 15-country international cohort studies of nuclear workers and of people living near nuclear reactors also indicates that radiation effects are not linear in terms of survival and incidence of cancer and other diseases and that these effects may be further accentuated as a function of age, health status and lifestyle variations ${ }^{[81,82]}$.

Application of low-dose (1.2-1.8 Gy) total body irradiation (TBI) in treatment of cancers, such as nonHodgkin's lymphoma, is considered to be an example of radiation hormesis ${ }^{[83,84]}$. This is due to the fact that low dose TBI did not kill cancer cells directly, but enhanced their removal by the immune system by increasing the proportion of cytotoxic $\mathrm{T}$ lymphocytes, helper-inducer $\mathrm{T}$ lymphocytes and helper $\mathrm{T}$ lymphocytes, while decreasing the proportion of the suppressor-inducer $\mathrm{T}$ lymphocytes and suppressor $\mathrm{T}$ lymphocytes ${ }^{[83,84]}$.

Although the exact mechanisms of how LDR brings about beneficial and longevity-promoting effects are not fully understood, there is evidence that LDR stimulates various repair and maintenance pathways as the cellular response to counteract the damage induced by radiation. These pathways include enhanced DNA repair, induction of DNA methylation, increased levels of antioxidative enzymes and increased removal of damaged macromolecules ${ }^{[6,85-88]}$.

\section{HYPERGRAVITY AND OTHER HORMETIC STRESSES IN AGING}

Hormetic effects of hypergravity have been studied mainly in Drosophila. Whereas life long exposure to hypergravity decreases the lifespan in rodents and fruitflies, a 2-week exposure to 3 or $5 \mathrm{~g}$ at earlier stages in life, resulted in an increase of $15 \%$ in the lifespan of male but not of female $D$. melanogaster ${ }^{[89,90]}$. In addition to longevity, other physiological and behavioural parameters, such as fecundity, fertility, locomotor activity, antioxidant enzyme activity, HSP levels and heat resistance, have also been analyzed ${ }^{[91]}$. Except for increased survival of hypergravity-exposed Drosophila under heat stress, no other clear cut patterns have been observed so far that can be associated with anti-aging effects of transient hypergravity ${ }^{[91]}$. It is also not clear why the longevity extending hormetic effects of hypergravity are restricted to male flies only. Studies on checking the anti-aging effects of hypergravity on various molecular biomarkers of aging, such as the level of macromolecular damage and other maintenance and repair pathways, are yet to be performed.

Other stresses: Some examples of other stresses that have been investigated with respect to their effects in 
aging and longevity include starvation, electromagnetic stress and mechanical stress, but the results obtained are not consistent or well understood. In one such study, chronic low-frequency $(10 \mathrm{~Hz})$ electric stimulation of young and old male Brown Norwegian rats resulted in more than 2-fold increase in the proportion of IIa slow muscle fibers and in the content of satellite cells ${ }^{[92]}$. An example of low-level mechanical stress having beneficial hormetic effects is the study showing that 20 minute burst of very low magnitude high frequency vibrations given to hind limbs of sheep increases the trabecular density by $34 \%$ in one year ${ }^{[93]}$. There is some indication that osteopontin synthesis in human dental osteoblasts is stimulated by low levels of mechanical stress ${ }^{[94]}$. The effects of repeated physical injuries on lifespan extension have been studied for a marine oligochaete Paranais litoralis, capable of posterior regeneration and of asexual reproduction ${ }^{[95]}$.

Another kind of stress that appears to have hormetic effects is the population density in early stages of life. For example, it has been shown in Drosophila that larval crowding can induce both nutritional limitation and high concentrations of waste products and can thus be considered as a stress for the larvae. Several studies have reported that raising larvae in such conditions increased the lifespan of adult flies. For instance, an increase in lifespan with increased larval density, between 5 and 100 larvae per $5 \mathrm{~cm}^{3}$ of food has been reported. Furthermore, it was reported that whereas the developmental time, starvation resistance, relative fat content and lifespan increased with larval density, viability was dramatically decreased ${ }^{[96]}$. However, in a separate study it was shown that larval crowding had no negative effect on viability but could increase the lifespan in D. melanogaster ${ }^{[97]}$.

\section{EXERCISE HORMESIS}

The well-documented beneficial effects of exercise occur in a paradoxical background of biochemical framework. It is well known that exercise increases the production of potentially harmful substances such as reactive oxygen and nitrogen species, other free radicals, acids and aldehydes ${ }^{[98-100]}$. The most significant physiological change that occurs during exercise is up to 20-fold enhanced mitochondrial respiration and oxidative phosphorylation leading to increased metabolic rate ${ }^{[99,100]}$. Prolonged exercise then leads to the formation and accumulation of acids and other metabolites, which are potentially powerful damaging agents. However, it should be pointed out that the type and extent of molecular and cellular damage occurring as a result of exercise depends on the intensity duration and the type of the exercise performed. Therefore, the consequences of exercise also depend on the severity of the damage and the ability of the organism to counteract and adapt. Generally, exercise's beneficial effects in the context of aging and longevity are best observed with moderate and repeated bouts of exercise interrupted by a period of normal daily life activity ${ }^{[99,100]}$.

Since the long term beneficial effects of exercise are considered to be achieved by upregulation of various pathways of maintenance and repair, exercise is one of the best examples of hormesis. Some of the main molecular pathways involved in bringing about the adaptive and hormetic effects of exercise are activation of nuclear factor $\mathrm{NFKB}$ signaling cascade involving various stress kinases and antioxidant genes ${ }^{[101,102]}$, enhanced anti-inflammatory responses, enhanced DNA repair and increased degradation of damaged proteins and other macromolecules by proteasomal and lysosomal pathways ${ }^{[98,103]}$. Another pathway which is active in realizing the hormetic effects of exercise is the stress response or HSP synthesis pathway in which the induction of various HSP, during and after exercise, has a variety of beneficial biological effects associated with $\mathrm{it}^{[16,104-107]}$. Increased levels of HSP provide several benefits including a protection against molecular damage occurrence and accumulation, which is a crucial aspect of aging.

\section{CALORIC RESTRICTION AS A HORMETIC INTERVENTION}

Chronic dietary caloric restriction (CR) of about $40 \%$ is the most commonly used intervention shown to extend the lifespan and to slow down the onset of a wide range of age-related changes in a variety of organisms, such as yeast, insects, rats, mice and monkeys. Beneficial effects of other $\mathrm{CR}$ regimens, such as chronic 25 and $8.5 \% \mathrm{CR}^{[108]}$ and intermittent $\mathrm{CR}$ (once or twice a week) have also been reported ${ }^{[109,110]}$ However, the universal applicability of CR as an antiaging and lifespan extending intervention, especially in human beings, is a highly debated issue at present ${ }^{[111-124]}$. In any case, some beneficial and health promoting effects of $\mathrm{CR}$ have been reported even for human beings. For example, long-term CR is reported to be highly effective in reducing the risk for atherosclerosis in humans ${ }^{[125]}$ and ameliorates the decline in diastolic function in humans ${ }^{[126]}$. An unintentional $\mathrm{CR}$ imposed on the participants of the Biosphere-2 experiment in 1991, due to the technical problems in the smooth functioning of various systems, also gave some indication of the beneficial effects of 
$\mathrm{CR}$, as measured by several physiologic, hematologic, hormonal and biochemical parameters ${ }^{[127]}$. Similarly, socio-economically based chronic under nutrition and low body mass index have been shown to improve certain DNA-repair parameters in peripheral blood lymphocytes of human subjects ${ }^{[128]}$.

A relatively short duration CR for six months has also been shown to have beneficial effects in humans by reducing the fasting insulin levels, body temperature and DNA damage ${ }^{[129]}$. Intermittent $\mathrm{CR}$ by periodic fasting has been shown to have a range of beneficial effects in rodents, including lifespan extension, glucose metabolism, neuronal protection, proteasomal stimulation and enhanced levels of chaperones ${ }^{[109,130-132]}$. Our recent pilot studies on checking the effects of periodic partial (80\%) fasting, once a week for $24 \mathrm{~h}$, by serum reduction in serially passaged human skin fibroblasts have shown an increase in the lysosomal autophagy and an extension of replicative lifespan ${ }^{[47]}$.

In order to understand the mechanisms for the wide ranging beneficial effects of $\mathrm{CR}$, hormesis has been suggested as a major explanation by considering $\mathrm{CR}$ as a low-intensity stressor ${ }^{[133-135]}$. The main evidence in support of the view that CR is a low-intensity stressor is its association with the moderate increase in plasma levels of glucocorticoid steroid stress hormones ${ }^{[135]}$. Another requirement for the hormesis hypothesis to explain the effects of $\mathrm{CR}$ is that $\mathrm{CR}$ should work through one or more pathways involved in stress response, molecular damage prevention and turnover and metabolic regulation. There is significant evidence for the hormetic action of CR through the promotion of maintenance and repair pathways, which include the following:

- Increase in nucleotide excision repair ${ }^{[136]}$

- Increase in the level of chaperones ${ }^{[132,137,138]}$ - Increase in the level of proteosomal

- Enhancement of lysosomal autophagy ${ }^{[139,140]}$

- Reduction in mitochondrial free radical generation and increase in mitochondrial uncoupling ${ }^{[108,141,142]}$

- A shift in the metabolic regulation involving sirtuins and insulin-dependent pathways ${ }^{[143-146]}$

\section{DIETARY HORMESIS AND HORMETINS}

Several dietary components, such as vitamins, antioxidants, trace elements, minerals, ethanol and even herbicides and pesticides have been shown to have typical hormetic dose response ${ }^{[147]}$. All such compounds (natural or synthetic), which bring about biologically beneficial effects by acting through one or more pathways of maintenance and repair and stress response, are termed as hormetins ${ }^{[148]}$. Recently, the hormetic effects of various vitamins and macro- and micro-minerals, including iron, iodine, fluorine, selenium and copper have been reviewed ${ }^{[149]}$. Additionally, the effects of zinc also show a typical hormetic dose response and its beneficial effects are considered to be achieved through stress response induced alterations in gene expression of various maintenance and repair pathways ${ }^{[150,151]}$.

Dietary intake of moderate amounts of ethanol has been shown to have memory enhancing beneficial effects in mice ${ }^{[152]}$. The cardio-protective, antioxidative and other beneficial effects of wine are considered to be due to flavonoid and non-flavonoid components, such as resveratrol ${ }^{[153]}$, which also have hormetic dose response. Resveratrol is considered to be a product of sunlight- and microbial-stress induced hormetic response $^{[154]}$. Several studies have reported the antiaging and longevity enhancing effects of resveratrol in nematodes, Drosophila and mice ${ }^{[145,146,154-156]}$. Since resveratrol's mode of action involves regulating various pathways of maintenance, repair and metabolic rate including induction of stress proteins, it qualifies to be called a hormetin $^{[157]}$.

Other potential hormetins are various antioxidants, including components of spices and other medicinal plants. Almost all antioxidants show hormetic dose response and become pro-oxidants above certain doses. Furthermore, in some cases such as alpha lipoic acid and coenzyme Q10, it is their pro-oxidant activity in producing hydrogen peroxide, which induces defensive responses, which are the basis of their ultimately beneficial effects ${ }^{[158]}$. Certain mimetics of superoxide dimutase claimed to have anti-aging effects also appear to work through hormetic pathways by inducing oxidative stress response ${ }^{[159-161]}$. It has also been argued that initial low level deposition of A-beta protein, that eventually leads to Alzheimer's disease, may actually have some protective hormetic role for neurons ${ }^{[162]}$. Even DNA damage products, for example thymidine dimers, have cytoprotective effects in the skin by inducing DNA repair pathways ${ }^{[86,163]}$.

Components of various medicinal plants used frequently in the Traditional Chinese Medicine (TCM) and in the Indian Ayurvedic system of medicine are claimed to have anti-aging effects, which appear to be achieved through hormetic pathways. For example, celasterols and paeoniflorin present in some medicinal herbs used in TCM, have cytoprotective effects and induce HSP in human cells ${ }^{[164,165]}$. Similarly, curcumin, 
which is the active component in the commonly used yellow food spice Haldi and is derived from the roots of Curcuma longa, is a co-inducer of HSP and has wide ranging biological effects depending on its dosage ${ }^{[166-168]}$. Whereas curcumin doses above 10 micro-mole have been reported to have antiinflammatory and anti-cancer effects in experimental studies ${ }^{[169,170]}$, at lower doses curcumin stimulates proteasome activity, enhances HSP induction after HS and stimulates sodium pump activity ${ }^{[47,148]}$. However, no studies have yet been performed on the long term and aging modulatory effects of above compounds.

Understanding the hormetic and interactive mode of action of natural and processed foods is a challenging field of research and has great potential in developing nutritional and other life style modifications for aging intervention and therapies. For example, it may be possible to develop multi-hormetin formulations as anti-aging drugs and nutriceuticals whose mode of action is through hormetic pathways by mild stress-induced stimulation of homeodynamic processes.

\section{CHALLENGES AND PERSPECTIVES FOR APPLYING HORMESIS}

Since hormetic effects of mild stress are normally observed to be quite moderate, some people find it difficult to envisage the biological significance of hormesis in terms of its application in human aging intervention and prevention ${ }^{[171,172]}$. However, it should be pointed out that although the initial hormetic effects may be relatively small when studied at the level of an individual biochemical step, often the final biological outcome, such as overall stress-tolerance, functional improvement and survival, is much larger, synergistic and pleiotropic. This suggests that hormesis is involved in the biological amplification of adaptive responses leading to the improvement in overall cellular functions and performance. Exercise is a good example of the biological amplification of beneficial effects of mild stress where it is not only the specific muscle targets which gain benefit, but improvements in the immune system, cardiovascular system, sex hormones, libido and mood are also well documented. A recent study performed on rats shows that exercise performed in a young age can have lifelong benefits on bone structure and strength ${ }^{[173]}$. This indicates that even moderate hormetic strengthening of homeodynamic networks can have much larger beneficial effects in terms of maintenance of functionality and prevention or delay of onset of age-related fraility.
The main promise and potential of hormesis as a modulator of aging lies in its mode of action. Since hormetic effects occur by involving a series of molecular and physiological processes, the final target of hormesis is the overall homeodynamic machinery of the living systems. Although hormesis-inducing stress may be targeted at a single pathway, the cascade of biological effects and their amplification results in the modulation and strengthening of the total homeodynamic ability. Increased efficiency of maintenance and repair pathways and decreased molecular heterogeneity are two of the major hallmarks of improved homeodynamics.

At present there is little knowledge of the interactive molecular pathways which, through a process of biological amplification, result in the maintenance and/or improvement of the physiological functions. Furthermore, in the case of human beings, the role of the mental state and psychological challenge in modulating various physiological functions, such as the immune response, stress hormone synthesis, gene expression, cardiac output and muscle strength are only beginning to be addressed. Therefore, practical applications of hormesis as an aging modulator in human beings is presently limited by several unresolved issues in the understanding of aging. For example, biogerontological research has demonstrated that the complex phenotype of aging is very individualistic and involves both genetic and environmental factors, specially the lifestyle factors ${ }^{[3]}$. One of the genetic factors that appears to be specially relevant to hormesis is the genetic variation in stress response, such as the polymorphism in heat shock protein genes ${ }^{[174-176]}$. Similar studies are required to identify individual genetic variations with regard to other pathways of maintenance, repair and stress response.

Therefore, in order to determine for an individual the hormetic level of a single stress or a combination of stresses one needs to know the genetic and lifestyle factors including the medical history of a person. A practical and successful hormetic regimen comprising physical, chemical, dietary and psychological stressors will certainly require the level of information equal to that needed to develop the so-called personalized medicine ${ }^{[177]}$. However, the established scientific foundations of hormesis pave the way for achieving that in not-so-distant future.

\section{REFERENCES}

1. Rattan, S.I.S., 2006. Theories of biological aging: Genes, proteins and free radicals. Free Radic. Res., 40: $1230-1238$. 
2. Rattan, S.I.S., 2007. Homeostasis, homeodynamics and aging., In Encyclopedia of Gerontology, Birren, J., (Ed.) Elsevier Inc: UK. pp: 696-699.

3. Rattan, S.I.S., 2007. The science of healthy aging. Genes, milieu and chance. Ann. N. Y. Acad. Sci., 1114: 1-10.

4. Parsons, P.A., 2002. Life span: does the limit to survival depend upon metabolic efficiency under stress? Biogerontol., 3: 233-241.

5. Parsons, P.A., 2003. From the stress theory of aging to energetic and evolutionary expectations for longevity. Biogerontol., 4: 63-73.

6. Parsons, P.A., 2003. Energy, stress and the invalid linear no-threshold premise: A generalization illustrated by ionizing radiation. Biogerontol., 4: 227-231.

7. Parsons, P.A., 2004. From energy efficiency under stress to rapid development and a long life in natural populations. Biogerontol., 5: 201-210.

8. Parsons, P.A., 2007. Energetic efficiency under stress underlies positive genetic correlations between longevity and other fitness traits in natural populations. Biogerontol., 8: 55-61.

9. Parsons, P.A., 2007. Antagonistic pleiotropy and the stress theory of aging. Biogerontol., 8: 613-617.

10. Rattan, S.I.S., 2001. Hormesis in biogerontology. Crit Rev Toxicol, 31: 663-664.

11. Rattan, S.I.S., 2001. Applying hormesis in aging research and therapy. Hum. Exp. Toxicol., 20: 281-285.

12. Rattan, S.I.S., 2004. Aging intervention, prevention and therapy through hormesis. J. Gerontol. Biol. Sci., 59A: 705-709.

13. Rattan, S.I.S., 2005. Anti-ageing strategies: Prevention or therapy? EMBO Reports, 6: S25-S29.

14. Rattan, S.I.S., 2008. Hormesis in aging. Ageing Res Rev, 7: 63-78.

15. Le Bourg, E. and S.I.S. Rattan, Eds. 2008. Mild Stress and Healthy Aging: Applying hormesis in aging research and interventions., Springer: Dordrecht, The Netherlands.

16. Verbeke, P., J. Fonager, B.F.C. Clark, S.I.S. Rattan, 2001. Heat shock response and ageing: Mechanisms and applications. Cell Biol. Int., 25: 845-857.

17. Sun, Y. and T.H. MacRae, 2005. The small heat shock proteins and their role in human disease. FEBS. J., 272: 2613-2627.

18. Shama, S., C.Y. Lai, J.M. Antoniazzi, J.C. Jiang and S.M. Jazwinski, 1998. Heat stress-induced life span extension in yeast. Exp. Cell Res., 245: 379-388.
19. Lithgow, G.J., T.M. White, S. Melov, T.E. Johnson, 1995. Thermotolerance and extended life-span conferred by single-gene mutations and induced by thermal stress. Proc. Natl. Acad. Sci., USA, 92: 7540-7544.

20. Johnson, T.E., 2002. A personal retrospective on the genetics of aging. Biogerontol., 3: 7-12.

21. Yokoyama, K., K. Fukumoto, T. Murakami, S. Harada, R. Hosono, R. Wadhwa, Y. Mitsui, S. Ohkuma, 2002. Extended longevity of Caenorhabditis elegans by knocking in extra copies of hsp70F, a homolog of mot-2 (mortalin)/mthsp70/Grp75. FEBS Lett, 516: 53-57.

22. Butov, A., T.E. Johnson, J. Cypser, I. Sannikov, M. Volkov, M. Sehl, A.I. Yashin, 2001. Hormesis and debilitation effects in stress experiments using the nematode worm Caenorhabditis elegans: The model of balance between cell damage and HSP level. Exp. Gerontol., 37: 57-66.

23. Michalski, A.I., T.E. Johnson, J.R. Cypser, A.I. Yashin, 2001. Heating stress patterns in Caenorhabditis elegans longevity and survivorship. Biogerontol., 2: 35-44.

24. Yashin, A.I., J.R. Cypser, T.E. Johnson, A.I. Michalski, S.I. Boyko, V.N. Novoseltsev, 2001. Ageing and survival after different doses of heat shock: The results of analysis of data from stress experiments with the nematode worm Caenorhabditis elegans. Mech Ageing Dev, 122: 1477-1495.

25. Cypser, J.R. and T.E. Johnson, 2002. Multiple stressors in Caenorhabditis elegans induce stress hormesis and extended longevity. J. Gerontol. Biol. Sci., 57A: B109-B114.

26. Cypser, J.R. and T.E. Johnson, 2003. Hormesis in Caenorhabditis elagans dauer-defective mutants. Biogerontol., 4: 203-214.

27. Olsen, A., M.C. Vantipalli and G.J. Lithgow, 2006. Lifespan extension of Caenorhabditis elegans following repeated mild hormetic heat treatments. Biogerontol., 7: 221-230.

28. Khazaeli, A.A., M. Tatar, S.D. Pletcher, J.W. Curtsinger, 1997. Heat-induced longevity extension in Drosophila. I. Heat treatment, mortality and thermotolerance. J. Gerontol. Biol. Sci., 52A: B48-B52.

29. Le Bourg, E., P. Valenti, P. Lucchetta and F. Payre, 2001. Effects of mild heat shocks at young age on aging and longevity in Drosophila melanogaster. Biogerontol., 2: 155-164.

30. Hercus, M.J., V. Loeschcke and S.I.S. Rattan, 2003. Lifespan extension of Drosophila melanogaster through hormesis by repeated mild heat stress. Biogerontol., 4: 149-156. 
31. Sørensen, J.G., T.N. Kristensen, V. Loeschcke, 2003. The evolutionary and ecological role of heat shock proteins. Ecology Letters, 6: 1025-1037.

32. Vermeulen, C.J. and V. Loeschcke, 2007. Longevity and the stress response in Drosophila. Exp Gerontol, 42: 153-159.

33. Sørensen, J.G., P. Sarup, T.N. Kristensen, V. Loeschcke, 2008. Temperature-induced hormesis in Drosophila., In Mild Stress and Healthy Aging: Applying hormesis in aging research and interventions, Le Bourg, E. and S.I.S. Rattan, (Eds.), Springer: Dordrecht, The Netherlands. pp: 65-80.

34. Minois, N., A.A. Khazaeli, J.W. Curtsinger, 2001. Locomotor activity as a function of age and life span in Drosophila melanogaster overexpressing hsp70. Exp Gerontol, 36: 1137-1153.

35. Minois, N. and S. Vaynberg, 2002. Fecundity and life span in transgenic Drosophila melanogaster overexpressing hsp70. Biogerontology, 3: 301-306.

36. Overgaard, J., J.G. Sørensen, S.O. Petersen, V. Loeschcke, M. Holmstrup, 2005. Changes in membrane lipid composition following rapid cold hardening in Drosophila melanogaster. J. Insect. Physiol., 51: 1173-1182.

37. Minois, N., 2000. Longevity and aging: Beneficial effects of exposure to mild stress. Biogerontol., 1: 15-29.

38. Holloszy, J.O. and E.K. Smith, 1986. Longevity of cold-exposed rats: A reevaluation of the rate of living theory. J. Appl. Physiol., 61: 1656-1660.

39. Kaul, S.C. and R. Wadhwa, Eds. 2003. Aging of cells in and outside the body. Biology of Aging and its Modulation, Rattan, S.I.S. (Ed)., Vol. 2. Kluwer Acad. Publ. Dordrecht.

40. Rattan, S.I.S., 1998. Repeated mild heat shock delays ageing in cultured human skin fibroblasts. Biochem. Mol. Biol. Int., 45: 753-759.

41. Verbeke, P., B.F.C. Clark and S.I.S. Rattan, 2000. Modulating cellular aging in vitro: Hormetic effects of repeated mild heat stress on protein oxidation and glycation. Exp. Gerontol., 35: 787-794.

42. Verbeke, P., B.F.C. Clark and S.I.S. Rattan, 2001. Reduced levels of oxidized and glycoxidized proteins in human fibroblasts exposed to repeated mild heat shock during serial passaging in vitro. Free Radic Biol. Med., 31: 1593-1602.

43. Verbeke, P., M. Deries, B.F.C. Clark and S.I.S. Rattan, 2002. Hormetic action of mild heat stress decreases the inducibility of protein oxidation and glycoxidation in human fibroblasts. Biogerontol., 3: 105-108.
44. Fonager, J., R. Beedholm, B.F.C. Clark, S.I.S. Rattan, 2002. Mild stress-induced stimulation of heat shock protein synthesis and improved functional ability of human fibroblasts undergoing aging in vitro. Exp. Gerontol., 37: 1223-1238.

45. Beedholm, R., B.F.C. Clark and S.I.S. Rattan, 2004. Mild heat stress stimulates proteasome and its $11 \mathrm{~S}$ activator in human fibroblasts undergoing aging in vitro. Cell Stress and Chaperones, 9: 49-57.

46. Nielsen, E.R., Y. Eskildsen-Helmond, S.I.S. Rattan, 2006. MAP-kinases and heat shockinduced hormesis in human fibroblasts during serial passaging in vitro. Ann. NY Acad. Sci., 1067: 343-348.

47. Rattan, S.I.S. and R.E. Ali, 2007. Hormetic prevention of molecular damage during cellular aging of human skin fibroblasts and keratinocytes. Ann. NY Acad. Sci., 1100: 424-430.

48. Berge, U., J. Behrens and S.I.S. Rattan, 2007. Sugar-induced premature aging and altered differentiation in human epidermal keratinocytes. Ann. NY Acad. Sci., 1100: 524-529.

49. Rattan, S.I.S., H. Sejersen, R.A. Fernandes, W. Luo, 2007. Stress-mediated hormetic modulation of aging, wound healing and angiogenesis in human cells. Ann. NY Acad. Sci., 1119: 112-121.

50. Park, H.G., S.I. Han, S.Y. Oh and H.S. Kang, 2005. Cellular responses to mild heat stress. Cell Mol. Life Sci., 62: 10-23.

51. Vaiserman, A.M., 2008. Irradiation and hormesis., In Mild Stress and Healthy Aging: Applying hormesis in aging research and interventions, Le Bourg, E. and S.I.S. Rattan, (Eds.), Springer: Dordrecht, The Netherlands. pp: 21-41.

52. Davey, W.P., 1917. The effect of X-rays on the length of life of Tribolium confusum. J. Exp. Zool., 22: 573-592.

53. Davey, W.P., 1919. Prolongation of life of Tribolium confusum apparently due to small doses of X-rays. J. Exp. Zool., 28: 447-458.

54. Cork, J.M., 1957. Gamma-radiation and longevity of the flour beetle. Radiat Res., 7: 551-557.

55. Ducoff, H.S., 1975. Form of the increased longevity of Tribolium after X-irradiation. Exp. Gerontol., 10: 189-193.

56. Lamb, M.J., 1964. The effect of radiation on the longevity of female Drosophila subobscura. J. Insect. Physiol., 10: 487-497.

57. Sacher, G.A., 1963. Effect of X-rays on the survival of Drosophila imagoes. Physiol. Zool., 36: 295-311. 
58. Allen, R.G. and R.S. Sohal, 1982. Life-lengthening effects of gamma-radiation on the adult housefly, Musca domestica. Mech Age Dev, 20: 369-375.

59. Vaiserman, A.M., N.M. Koshel, A.Y. Litoshenko, T.G. Mozzhukhina and V.P. Voitenko, 2003. Effects of X-irradiation in early ontogenesis on the longevity and amount of the S1 nuclease-sensitive DNA sites in adult Drosophila melanogaster. Biogerontol., 4: 9-14.

60. Vaiserman, A.M., N.M. Koshel, L.V. Mechova and V.P. Voitenko, 2004. Cross-life stage and crossgenerational effects of $\mathrm{g}$ irradiation at the egg stage on Drosophila melanogaster life histories. Biogerontol., 5: 327-337.

61. Vaiserman, A.M., N.M. Koshel and V.P. Voitenko, 2004. Effect of X-irradiation at larval stage on adult lifespan in Drosophila melanogaster. Biogerontol., 5: 49-54.

62. Caratero, A., M. Courtade, L. Bonnet, H. Planel and C. Caratero, 1998. Effect of continuous gamma irradiation at a very low dose on the life span of mice. Gerontol., 44: 272-276.

63. Calabrese, E.J. and L.A. Baldwin, 2000. The effects of gamma rays on longevity. Biogerontol., 1: 309-319.

64. Ina, Y. and K. Sakai, 2005. Further study of prolongation of life span associated with immunologic modification by chronic low-doserate irradiation in MRL-lpr/lpr mice: Effects of whole-life irradiation. Radiat. Res., 163: 418-423.

65. Ina, Y., H. Tanooka, T. Yamada and K. Sakai, 2005. Suppression of thymic lymphoma induction by life-long low-dose-rate irradiation accompanied by immune activation in C57BL/6 mice. Radiat. Res., 163: 153-158.

66. Ordy, J.M., T. Samorajski, W. Zeman and H.J. Curtis, 1967. Interaction effects of environmental stress and deutron irraridation of the brain on mortality and longevity of C57BL/10 mice. Proc. Soc. Exp. Biol. Med., 126: 184-190.

67. Johnson, T.E. and P.S. Hartman, 1988. Radiation effects on life span in Caenorhabditis elegans. J. Gerontol., 43: B137-141.

68. Watanabe, M., M. Suzuki, K. Suzuki, K. Nakano and K. Watanabe, 1992. Effect of multiple irradiation with low doses of gamma-rays on morphological transformation and growth ability of human embryo cells in vitro. Int. J. Radiat. Biol., 62: 711-718.

69. Holliday, R., 1991. A re-examination of the effects of ionizing radiation on lifespan and transformation of human diploid fibroblasts. Mutat. Res., 256: 295-302.
70. Tsutsui, T., Y. Tanaka, Y. Matsudo, K. Hasegawa, T. Fujino, S. Kodama and J.C. Barrett, 1997. Extended lifespan and immortalization of human fibroblasts induced by X-ray irradiation. Mol. Carcinog., 18: 7-18.

71. Suzuki, K., S. Kodama and M. Watanabe, 1998. Suppressive effects of low-dose preirradiation on genetic instability induced by $X$ rays in normal embryonic cells. Radiat. Res., 150: 656-662.

72. Suzuki, K., S. Kodama and M. Watanabe, 2001. Extremely low-dose ionizing radiation causes activation of mitogen-activated protein kinase pathway and enhances proliferation of normal human diploid cells. Cancer Res., 61: 5396-5401.

73. Suzuki, M., Z. Yang, K. Nakano, F. Yatagai, K. Suzuki, S. Kodama and M. Watanabe, 1998. Extension of in vitro life-span of gamma-irradiated human embryo cells accompanied by chromosome instability. J. Radiat Res., 39: 203-213.

74. Wyngaarden, K.E.V. and E.K.J. Pauwels, 1995. Hormesis: Are low doses of ionizing radiation harmful or beneficial? Eur. J. Nucl. Med., 22: 481-486.

75. Okajima, S., M. Mine and T. Nakamura, 1985. Mortality of registered A-bomb survivors in Nagasaki, Japan, 1970-1984. Radiat. Res., 103: 419-31.

76. Hayakawa, N., M. Ohtaki, H. Ueoka, M. Matsuura, M. Munaka and M. Kurihara, 1989. Mortality statistics of major causes of death among atomic bomb survivors in Hiroshima Prefecture from 1968 to 1982. Hiroshima J. Med. Sci., 38: 53-67.

77. Mine, M., Y. Okumura, M. Ichimaru, T. Nakamura and S. Kondo, 1990. Apparently beneficial effect of low to intermediate doses of Abomb radiation on human lifespan. Int. J. Radiat Biol., 58: 1035-43.

78. Cologne, J.B. and D.L. Preston, 2000. Longevity of atomic-bomb survivors. Lancet, 356: 303-307.

79. Atkinson, W.D., D.V. Law, K.J. Bromley and H.M. Inskip, 2004. Mortality of employees of the United Kingdom Atomic Energy Authority, 194697. Occup. Environ. Med., 61: 577-585.

80. Nambi, K.S. and S.D. Soman, 1987. Environmental radiation and cancer in India. Health Phys., 52: 653-657.

81. Cardis, E., M. Vrijheid and M. Blettner, et al. 2007. The 15-Country Collaborative Study of Cancer Risk among Radiation Workers in the Nuclear Industry: estimates of radiation-related cancer risks. Radiat. Res., 167: 396-416. 
82. Vrijheid, M., E. Cardis and P. Ashmore, et al. 2007. Mortality from diseases other than cancer following low doses of ionizing radiation: Results from the 15-Country Study of nuclear industry workers. Int. J. Epidemiol., 36: 1126-1135.

83. Safwat, A., 2000. The role of low-dose total body irradiation in treatment of non-Hodgkins lymphoma: A new look at an old method. Radiother Oncol., 56: 1-8.

84. Safwat, A., 2008. Clinical applications of low-dose whole body irradiation hormesis., In: Mild stress and healthy aging: Applying Hormesis in Aging Research and Interventions, Le Bourg E. and S.I.S. Rattan, (Eds.), Springer: Dordrecht, The Netherlands. pp: 157-170.

85. Wolff, S., 1996. Aspects of the adaptive response to very low doses of radiation and other agents. Mutat. Res., 358: 135-42.

86. Eller, M.S., T. Maeda, C. Magnoni, D. Atwal and B.A. Gilchrest, 1997. Enhancement of DNA repair in human skin cells by thymidine dinucleotides: Evidence for a p53-mediated mammalian SOS response. Proc. Natl. Acad. Sci. USA, 94: 12627-12632.

87. Pollycove, M. and L.E. Feinendegen, 2001. Biologic responses to low doses of ionizing radiation: Detriment versus hormesis. Part 2. Dose responses of organisms. J. Nucl. Med., 42: $26 \mathrm{~N}-37 \mathrm{~N}$

88. Feinendegen, L.E., 2005. Evidence for beneficial low level radiation effects and radiation hormesis. Brit. J. Radiol., 78: 3-7.

89. Le Bourg, E., N. Minois, P. Bullens and P. Baret, 2000. A mild stress due to hypergravity exposure at young age increases longevity in Drosophila melanogaster males. Biogerontol., 1: 145-55.

90. Minois, N., 2006. The hormetic effects of hypergravity on longevity and aging. DoseResponse, 4: 123-132.

91. Le Bourg, E., 2008. Hypergravity in Drosophila melanogaster., In Mild Stress and Healthy Aging: Applying hormesis in aging research and interventions, Le Bourg E. and S.I.S. Rattan, (Eds.) Springer: Dordrecht, The Netherlands. pp: 63-63.

92. Putman, C.T., K.R. Sultan, T. Wassmer, J.A. Bamford, D. Skorjanc and D. Pette, 2001. Fiber-type transitions and satellite cell activation in low-frequency-stimulated muscles of young and aging rats. J. Gerontol. Biol. Sci., 56A: B510-B519.

93. Rubin, C., A.S. Turner, S. Bain, C. Mallinckrodt and K. McLeod, 2001. Low mechanical signals strengthen long bones. Nature., 412: 603-604.
94. Liu, D., B.B. Vandahl, S. Birkelund, L.B. Nielsen and B. Melsen, 2004. Secretion of osteopontin fom MG-63 cells under a physiological level of mechanical strain in vitro-a $35 \mathrm{~S}$ incorporation approach. Eur. J. Orthodont., 26: 143-149.

95. Martínez, D.E., 1996. Rejuvenation of the disposable soma: Repaeated injury extends lifespan in an asexual annelid. Exp. Gerontol., 31: 699-704.

96. Minois, N. and S.I.S. Rattan, 2003. Hormesis in aging and longevity., In: Modulating Aging and Longevity, Rattan, S.I.S. (Ed.): Kluwer Academic Publishers: Dordrecht. pp: 127-137.

97. Sørensen, J.G. and V. Loeschcke, 2001. Larval crowding in Drosophila melanogaster induces Hsp70 expression and leads to increased adult longevity and adult thermal stress resistance. J. Insect. Physiol., 47: 1301-1307.

98. Radak, Z., H.Y. Chung, S. Goto, 2005. Exercise and hormesis: Oxidative stress-related adaptation for successful aging. Biogerontol., 6: 71-75.

99. Ji, L.L., M.C. Gomez-Cabrera, J. Vina, 2006. Exercise and hormesis: Activation of cellular antioxidant signaling pathway. Ann. NY Acad. Sci., 1067: 425-35.

100.Ji, L.L., 2008. Physical activity: A strong stimulant for hormesis during aging., In: Mild Stress and Healthy Aging: Applying hormesis in aging reserch and interventions, Le Bourg E. and S.I.S. Rattan, (Eds.), Springer: Dordrecht, The Netherlands. pp: 99-114.

101. Wakatsuki, T., J. Schlessinger and E.L. Elson, 2004. The biochemical response of the heart to hypertension and exercise. Trends Biochem. Sci., 29: 609-617.

102.Ji, L.L., 2006. Oxidative stress and antioxidative defense: effects of aging and exercise., In Oxidative Stress, Exercise and Aging, Alessio H.M. and A.E. Hagerman, (Eds.), Imperial College Press: London. pp: 85-108.

103.Short, K.R., J.L. Vittone, M.L. Bigelow, D.N. Proctor and K Proctor and K.S. Nair, 2004. Age and aerobic exercise J. Phsyiol. Endocrinol. Metab., 286: E92-E101.

104. Atalay, M., N.K. Oksala, D.E. Laaksonen, S. Khanna, C. Nakao, J. Lappalainen, S. Roy, O.O. Hanninen, C.K. Sen, 2004. Exercise training modulates heat shock protein response in diabetic rats. J. Appl. Physiol. 97: 605-611.

105.Lancaster, G.I., K. Møller, B. Nielsen, N.H. Secher, M.A. Febbraio, L. Nybo, 2004. Exercise induces the release of heat shock protein 72 from the human brain in vivo. Cell Stress and Chaperones, 9: 276-280. 
106.Gonzales, B. and R. Manso, 2004. Induction, modification and accumulation of HSP70s in the rat liver after acute exercise: Early and late responses. J. Physiol., 556: 369-385.

107.McArdle, A., W.H. Dillmann, R. Mestril, J.A. Faulkner and M.J. Jackson, 2004. Overexpression of HSP70 in mouse skeletal muscle protects against muscle damage and agerelated muscle dysfunction. FASEB J., 18: 355-357.

108.Gomez, J., P. Caro, A. Naudi, M. PorteroOtin, R. Pamplona, G. Barja, 2007. Effect of 8.5 and $25 \%$ caloric restriction on mitochondrial free radical production and oxidative stress in rat liver. Biogerontol., 8: 555-66.

109.Anson, R.M., Z. Guo, R. de Cabo, T. Lyun, M. Rios, A. Hagepanos, D.K. Ingram, M.A. Lane and M.P. Mattson, 2003. Intermittent fasting dissociates beneficial effects of dietary restriction on glucose metabolism and neuronal resistance to injury from calorie restriction. Proc. Natl. Acad. Sci. USA, 100: 6216-6220.

110.Martin, B., M.P. Mattson and S. Maudsley, 2006. Caloric restriction and intermittent fasting: Two potential diets for successful aging. Age Res. Rev., 5: 332-353.

111.Le Bourg, E. and S.I.S. Rattan, 2006. Can dietary restriction increase longevity in all species, particularly in human beings? Introduction to a debate among experts. Biogerontol., 7: 123-125.

112.Braeckman, B.P., L. Demetrius and J.R. Vanflateren, 2006. The dietary restriction effects in C. elegans and humans: Is the worm a one millimeter human? Biogerontol., 7: 127-133.

113.Holliday, R., 2006. Food, fertility and longevity. Biogerontol., 7: 139-141.

114.Le Bourg, E., 2006. Dietary restriction would probably not increase longevity in human beings and other species able to leave unsuitable environments. Biogerontol., 7: 149-152.

115. Masoro, E.J., 2006. Caloric restriction and aging: controversial issues. J. Gerontol., A Biol. Sci. Med. Sci., 61: 14-9.

116.Masoro, E.J., 2006. Dietary restriction-induced life extension: a broadly based biological phenomenon. Biogerontol., 7: 153-155.

117.Goto, S., 2006. Health span extension by later-life caloric or dietary restriction: A view based on rodent studies. Biogerontol., 7: 135-138.

118.Ingram, D.K., G.S. Roth, M.A. Lane, M.A. Ottinger, S. Zou, R. de Cabo and J.A. Mattison, 2006. The potential for dietary restriction to increase longevity in humans: Extrapolation from monkey studies. Biogerontol., 7: 143-148.
119.Phelan, J.P. and M.R. Rose, 2006. Caloric restriction increases longevity substantially only when the reaction norm is steep. Biogerontol., 7: 161-164.

120.Mockett, R.J., T.M. Cooper, W.C. Orr and R.S. Sohal, 2006. Effects of caloric restriction are species-specific. Biogerontol., 7: 157-160.

121.Shanley, D.P. and T.B. Kirkwood, 2006. Caloric restriction does not enhance longevity in all species and is unlikely to do so in humans. Biogerontol., 7: $165-168$.

122. Weindruch, R., 2006. Will dietary restriction work in primates? Biogerontol., 7: 169-171.

123.Yu, B.P., 2006. Why calorie restriction would work for human longevity. Biogerontol, 7: 179-182.

124.Dirks, A.J. and C. Leeuwenburgh, 2006. Caloric restriction in humans: potential pitfalls and health concerns. Mech. Ageing. Dev., 127: 1-7.

125.Fontana, L., T.E. Meyer, S. Klein and J.O. Holloszy, 2004. Long-term calorie restriction is highly effective in reducing the risk for atherosclerosis in humans. Proc. Natl. Acad. Sci. USA, 10: 6659-6663.

126.Meyer, T.E., S.K. Kovács, A.A. Ehsani, S. Klein, J.O. Holloszy and L. Fontana, 2006. Long-term caloric restriction ameliorates the decline in diastolic functions in humans. J. Am. Coll. Cardiol., 47: 398-402.

127.Walford, R.L., D. Mock, R. Verdery, T. MacCallum, 2002. Calorie restriction in biosphere 2: alterations in physiologic, hematologic, hormonal and biochemical parameters in humans restricted for a 2-year period. J. Gerontol. Biol. Sci., 57A: B211-B224.

128.Raji, N.S., A. Surekha and K. Subba Rao, 1998. Improved DNA-repair parameters in PHAstimulated peripheral blood lymphocytes of human subjects with low body mass index. Mech. Ageing. Dev., 104: 133-148.

129.Heilbronn, L.K., d.J. L., M.I. Frisard, J.P. DeLany, D.E.R. Larson-Meyer, J., T. Nguyen, C.K. Martin, J. Volaufova, M.M. Most, F.L. Greenway, S.R. Smith, W.A. Deutsch, D.A. Williamson and E. Ravussin, 2006. Effect of 6-month calorie restriction on biomarkers of longevity, metabolic adaptation and oxidative stress in overweight individuals. JAMA, 295: 1539-1548.

130. Sogawa, H. and C. Kubo, 2000. Influence of shortterm repeated fasting on the longevity of female (NZB x NZW)F1 mice. Mech. Ageing. Dev., 115: 61-71. 
131.Sharma, S. and G. Kaur, 2005. Neuroprotective potential of dietary restriction against kainateinduced excitotoxicity in adult male Wistar rats. Brain Res Bull, 67: 482-491.

132.Bonelli, M.A., S. Desenzani, G. Cavallini, A. Donati, A.A. Romani, E. Bergamini, A.F. Borghetti, 2008. Low-level caloric restriction rescues proteasome activity and Hsc70 level in liver of aged rats. Biogerontol, 9: 1-10

133.Parsons, P.A., 2000. Caloric restriction, metabolic efficiency and hormesis. Hum. Exp. Toxicol., 19: 345-347.

134.Yu, B.P. and H.Y. Chung, 2001. Stress resistance by caloric restriction for longevity. Ann. NY Acad. Sci., 928: 39-47.

135.Masoro, E.J., 2007. The role of hormesis in life extension by dietary restriction. Interdiscip Top Gerontol, 35: 1-17.

136.Guo, Z., A. Heydari and A. Richardson, 1998. Nucleotide excision repair of actively transcribed versus nontranscribed DNA in rat hepatocytes: Effect of age and dietary restriction. Exp. Cell Res., 245: 228-238.

137. Selsby, J.T., A.R. Judge, D. Yimlamai, C. Leeuwenburgh and S.L. Dodd, 2005. Life long calorie restricition increases heat shock proteins and proteasome activity in soleus muscle of Fischer 344 rats. Exp. Gerontol., 40: 37-42.

138.Hahn, J.S., Z.W. Hu, D.J. Thiele and V.R. Iyer, 2004. Genome-wide analysis of the biology of stress responses through heat shock trasncription factor. Mol. Cell Biol., 24: 5249-5256.

139.Bergamini, E., G. Cavallini, A. Donati and Z. Gori, 2003. The anti-ageing effects of calorie restriction may involve stimulation of macroautophagy and lysosomal degradation and can be intensified pharmacologically. Biomed Pharmaco, 57: 203-208.

140.Cuervo, A.M. and J.F. Dice, 2000. Age-related decline in chaperone-mediated autophagy. J. Biol. Chem., 275: 31505-31513.

141.Liu, D., S.L. Chan, N.C. de Souza-Pinto, J.R. Slevin, R.P. Wersto, M. Zhan, K. Mustafa, R. de Cabo and M.P. Mattson, 2006. Mitochondrial UCP4 mediates an adaptive shift in energy metabolism and increases the resistance of neurons to metabolic and oxidative stress. Neuromolecular Med., 8: 389-414.

142. Crescenzo, R., L. Lionetti, M.P. Mollica, M. Ferraro, E. D'Andrea, D. Mainieri, A.G. Dulloo, G. Liverini and S. Iossa, 2006. Altered skeletal muscle subsarcolemmal mitochondrial compartment during catch-up fat after caloric restriction. Diabetes, 55: 2286-2293.

143.Nemoto, S., M.M. Fergusson and T. Finkel, 2004. Nutrient availability regulates SIRT1 through a forkhead-dependent pathway. Science, 306: 21052108.
144.Cohen, H.Y., C. Miller, K.J. Bitterman, N.R. Wall, B. Hekking, B. Kessler, K.T. Howitz, M. Gorospe, R. de Cabo and D.A. Sinclair, 2004. Calorie restriction promotes mammalian cell survival by inducing the SIRT1 deacetylase. Science, 305: 390-392.

145. Wood, J.G., B. Rogina, S. Lavu, K.T. Howitz, S.L. Helfand, M. Tatar and D.A. Sinclair, 2004. Sirtuin activators mimic caloric restriction and delay ageing in metazoans. Nature, 430: 686-689.

146.Rogina, B. and S.L. Helfand, 2004. Sir2 mediates longevity in the fly through a pathway related to calorie restriction. Proc. Natl. Acad. Sci. USA, 101: 15998-16003.

147.Calabrese, E. and R. Blain, 2005. The hormetic database: An overview. Toxicol. Appl. Pharmacol., 202: 289-301.

148.Ali, R.E. and S.I.S. Rattan, 2006. Curcumin's biphasic hormetic response on proteasome activity and heat shock protein synthesis in human keratinocytes. Ann. NY Acad. Sci., 1067: 394-399.

149.Hayes, D.P., 2007. Nutritional hormesis. Eur J Clin Nutr, 61: 147-159.

150.Mocchegiani, E., M. Muzzioli, R. Giacconi, 2000. Zinc, metallothioneins, immune responses, survival and ageing. Biogerontol., 1: 133-143.

151.Mocchegiani, E., L. Rink, M.A. Blasco, 2006. Zinc and ageing (ZINCAGE project). Biogerontol., 7: 305-306.

152.Ritzmann, R.F., A. Glasky, A. Steinberg, C.L. Melchior, 1994. The interaction of ethanol with the cognitive enhancers tacrine, physostigmine and AIT-082. J Gerontol, 49: B51-B53.

153.Corder, R., W. Mullen, N.Q. Khan, S.C. Marks, E.G. Wood, M.J. Carrier and A. Crozier, 2006. Red wine procyanidins and vascular health. Nature, 444: 566

154.Lamming, D.W., J.G. Wood and D.A. Sinclair, 2004. Small molecules that regulate lifespan: Evidence for xenohormesis. Mol. Microbiol, 53: 1003-1009.

155. Valenzano, D.R., E. Terzibasi, T. Genade, A. Cattaneo, L. Domenici and A. Cellerino, 2006. Resveratrol prolongs lifespan and retards the onset of age-related markers in a short-lived vertebrate. Curr. Biol., 16: 296-300.

156.Baur, J.A., K.J. Pearson, N.L. Price and H.A. Jamieson, et al., 2006. Reseveratrol improves health and survival of mice on a high-calorie diet. Nature, 443: 337-342.

157.Putics, A., E.M. Végh, P. Csermely and C. Soti, 2008. Resveratrol induces the heat-shock response and protects human cells from severe heat stress. Antiox. Red. Sign., 10: 1-11. 
158.Linnane, A.W., M. Kios and L. Vitetta, 2007. Healthy aging: Regulation of the metabolome by cellular redox modulation and prooxidant signaling systems: The essential roles of superoxide anion and hydrogen peroxide. Biogerontol., 8: 445-467.

159.Melov, S., J. Ravenscroft, S. Malik, M.S. Gill, D.W. Walker, P.E. Clayton, D.C. Wallace, B. Malfroy, S.R. Doctrow and G.J. Lithgow, 2000. Extension of life-span with superoxide dismutase/catalase mimetics. Sci., 289: 1567-1569.

160.Liu, R., I.Y. Liu, X. Bi, R.F. Thompson, S.R. Doctrow, B. Malfroy and M. Baudry, 2003. Reversal of age-related learning deficits and brain oxidative stress in mice with superoxide dismutase/catalase mimetics. Proc. Natl. Acad. Sci. USA, 100: 8526-8531.

161.Keany, M., F. Matthijssens, M. Sharpe, J. Vanfleteren and D. Gems, 2004. Superoxide dismutase mimetics elevate superoxide dismutase activity in vivo but do not retard aging in the nematode Caenorhabditis elegans. Free Rad. Biol. Med., 37: 239-250.

162.Rubinsztein, D.C., 2006. The roles of intracellular protein-degradation pathways in neurodegeneration. Nature, 443: 780-786.

163.Goukassian, D.A., E. Helms, H. Van Steeg, C. van Oostrom, J. Bhawan and B.A. Gilchrest, 2004. Topical DNA oligonucleotide therapy reduces UVinduced mutations and photocarcinogenesis in hairless mice. Proc. Natl. Acad. Sci. USA, 101: 3933-3938.

164.Westerheide, S.D., J.D. Bosman, B.N.A. Mbadugha, T.L.A. Kawahara, G. Matsumoto, S. Kim, W. Gu, J.P. Devlin, R.B. Silverman and R.I. Morimoto, 2004. Celastrols as inducers of the heat shock response and cytoprotection. J. Biol. Chem., 279: 56053-56060.

165. Yan, D., K. Saito, Y. Ohmi, N. Fujie and K. Ohtsuka, 2004. Paeoniflorin, a novel heat shock protein-inducing compound. Cell Stress and Chaperones, 9: 378-389.

166.Dunsmore, K.E., P.G. Chen and H.R. Wong, 2001. Curcumin, a medicinal herbal compound capable of inducing heat shock response. Crit. Care. Med., 29: 2199-2204.

167.Cronin, J.R., 2003. Curcumin: Old spice is a new medicine. Alternative Complement Therap, Feb: 3438.
168.Joe, B., M. Vijaykumar and B.R. Lokesh, 2004. Biological properties of curcumin-cellular and molecular mechanism of action. Crit. Rev. Food Sci. Nutr., 44: 97-111.

169.Rashmi, R., T.R. Santhosh Kumar and D. Karunagaran, 2003. Human colon cancer cells differ in their sensitivity to curcumin-induced apoptosis and heat shock protects them by inhibiting the release of apoptosis-inducing factor and caspases. FEBS Lett, 538: 19-24.

170.Moos, P.J., K. Edes, J.E. Mullally and F.A. Fitzpatrick, 2004. Curcumin impairs tumour suppressor p53 function in colon cancer cells. Carcinogenesis, 25: 1611-1617.

171.Zapponi, G.A. and I. Marcello, 2006. Low-dose risk, hormesis, analogical and logical thinking. Ann. NY Acad. Sci., 1076: 839-857.

172.Thayer, K.A., R. Melnick, J. Huff, K. Burns and D. Davis, 2006. Hormesis: A new religion? Environ Health Perspect, 114: A632-633.

173.Warden, S.J., R.K. Fuchs, A.B. Castillo, I.R. Nelson and C.H. Turner, 2007. Exercise when young provides lifelong benefits to bone structure and strength. J. Bone. Miner. Res., 22: 251-259.

174. Singh, R., S. Kølvraa, P. Bross, N. Gregersen, B.A. Nexø, H. Frederiksen, K. Christensen and S.I.S. Rattan, 2004. Association between low selfrated health and heterozygosity for -110A-C polymorphism in the promoter region of HSP70-1 in aged Danish twins. Biogerontol., 5: 169-176.

175.Singh, R., S. Kølvraa, P. Bross, U.B. Jensen, N. Gregersen, Q. Tan, C. Knudese and S.I.S. Rattan, 2006. Reduced heat shock response in human mononuclear cells during aging and its association with polymorphisms on HSP70 genes. Cell Stress Chaperones, 11: 208-215.

176.Singh, R., S. Kølvraa and S.I.S. Rattan, 2007. Genetics of longevity with emphasis on the relevance of HSP70 genes. Frontiers in Sci., 12: 4504-4513.

177.Bains, W., 2008. Truly personalised medicine: Self-experimentation in medical discovery. Med. Hypotheses. 70: 714-718. 